\title{
CAMPOS, SÁ-CARNEIRO E ALMADA: ORIENTALISMO NO PRIMEIRO NÚMERO DE ORPHEU ${ }^{1}$
}

Duarte Drumond Braga ${ }^{2}$

Recebido: 03/04/2016

Aprovado: 16/05/2016

Resumo: No primeiro número de Orpheu é possível encontrar três presenças bastante significativas do discurso orientalista, isto é, de uma tradição discursiva europeia de representação da alteridade "oriental": "Opiário", de Álvaro de Campos; "Distante Melodia", de Mário de Sá-Carneiro e "A Taça de Chá" de Almada Negreiros. Se o orientalismo é uma conhecida marca das estéticas finisseculares, importa contudo interpretar este fenómeno à luz do surto da estética modernista em Portugal. O presente ensaio procura fazer ver como, nos três casos, o que ocorre não é tanto a presença de uma herança finissecular, mas uma complexa desconstrução do discurso orientalista que poderia ser tomada como a principal característica de um Orientalismo Modernista Português.

Palavras-Chave: Estética Modernista - Orientalismo desconstruído - Álvaro de Campos - Mário de Sá-Carneiro - Almada Negreiros

\section{CAMPOS, SÁ-CARNEIRO AND ALMADA: ORIENTALISM IN THE FIRST NUMBER OF ORPHEU}

\begin{abstract}
In the first number of Orpheu there are three very significant presences of Orientalist discourse, that is, of a European discursive tradition that seeks to represent "Oriental" otherness: "The Tea Cup", by Almada Negreiros, "Opiário", by Álvaro de Campos and "Distant Melody" by Mário de Sá-Carneiro. Although Orientalism is a well known marker of fin-de-siècle aesthetics, it should in this case be framed as part of the outbreak of Modernist aesthetics in Portugal. This paper argues that these poems should not be read as a mere Decadentist-Symbolist heritage, but instead as a complex deconstruction of orientalist discourse that could be taken as the main characteristic of a Modernist Portuguese Orientalism.
\end{abstract}

Keywords: Modernist Aesthetics - Deconstructed Orientalism - Álvaro de Campos - Mário de SáCarneiro - Almada Negreiros

\footnotetext{
${ }^{1}$ A Fundação de Amparo à Pesquisa do Estado de São Paulo apoiou a pesquisa para este texto (número do processo 2014/00829-8). Texto oriundo do Projeto Temático da Fundação de Amparo à Pesquisa do Estado de São Paulo (número de processo 2014/15657-8).

2 Bolsista de Pós-Doutoramento da Fundação de Amparo à Pesquisa da Universidade de São Paulo na Universidade de São Paulo.
} 


\section{Introdução}

Pode causar surpresa o fato de só agora, no início do século XXI, o orientalismo literário português começar a ser estudado de forma sistemática. Afinal, pouco se tem refletido sobre a presença das representações do que se pode designar como Oriente ${ }^{3}$ na literatura europeia com a mais antiga tradição de contato com a Ásia. Ao contrário dos casos inglês, francês ou alemão - tradições orientalistas jovens, mas mais poderosas em termos de constituição de um conhecimento organizado sobre esses territórios -, a principal contribuição da tradição portuguesa passou pela inauguração e fixação, de forma decisiva, de algumas imagens do Oriente na cultura europeia. Essa presença é mais intensa nos séculos XVI e XVII, o que textos como Os Lusíadas ou A Peregrinação mostram. No século XIX, confirma-se o eclipse político e económico do Oriente colonial português que começara a partir da segunda metade do século XVII. Mesmo assim, o Oriente continua sendo presença discreta, mas constante ${ }^{4}$ na literatura portuguesa.

É no fim do século XIX que, segundo a minha leitura, nasce o moderno orientalismo literário português, pois este é o momento da conjunção entre a crise identitária de uma nação que se expandiu para Oriente e o influxo da estética orientalizante francesa e, em menor grau, inglesa da virada do século. É precisamente isso que temos em Camilo Pessanha, Alberto Osório de Castro ou Wenceslau de Moraes. Nestes autores finisseculares se combina a necessidade de reflexão acerca do legado oriental em Portugal, com a necessidade de o dizer e de o revisitar numa linguagem mais plástica, mediada pelas representações que a França e a Inglaterra agenciavam em relação a seus próprios Orientes. Aqui se formam duas linhas de sentido que, embora independentes, se combinam em vários autores: o orientalismo de viés colonial-imperial, revisitando os velhos temas,

\footnotetext{
3 O vocábulo Oriente não pode, em si mesmo, referendar uma geografia; é um topos que se alimenta de várias geografias. Edward Said, propõe, em Orientalismo (1978), entender o Oriente como uma atribuição que é conferida por um determinado "modo do discurso", e daí a famosa expressão "Oriente orientalizado" (SAID, 2004, p. 34). Como afirma o ensaísta palestiniano, não existe Oriente sem Ocidente: “(...) o Oriente não é um facto inerte da natureza. Não está ali, do mesmo modo que o Ocidente também não esta exactamente ali. (...) esses lugares, regiões e sectores geográficos que constituem o Oriente e o Ocidente, enquanto entidades geográficas e culturais - para já não dizer históricas - são criações do homem. Por conseguinte, tanto como o Ocidente, o Oriente é uma ideia que tem história e uma tradição de pensamento, de imagens, e um vocabulário que lhe deram uma realidade e uma presença no e para o Ocidente" (SAID, 2004, p. 5).

${ }^{4}$ Isto será suficiente para rever afirmações da crítica que sustentaram, a meu ver de forma apressada, que o romantismo português nao foi orientalista, mas algo bem doméstico. Sem dúvida não em Herculano ou Garrett, mas o mesmo não se poderá dizer para autores da segunda geração romântica como Tomas Ribeiro ou Soares de Passos.
} 
narrativas e figuras do "Oriente Português" quinhentista, e o orientalismo tomado de empréstimo ao esteticismo francês finissecular, sem referências à tradição portuguesa.

São estas duas linhas que chegam ao primeiro número da revista Orphen (1915) ${ }^{5}$. Como a pesquisa nesta matéria é ainda incipiente, não foi valorizada a presença muito evidente do orientalismo neste número da revista, como um todo, a saber: no "Opiário" de Álvaro de Campos; em "Distante Melodia" de Mário de Sá-Carneiro; em "Taça de Chá" de Almada Negreiros; e ainda em outros autores, como Alfredo Pedro Guisado ou Ângelo de Lima (este no segundo número), que deixarei para outro ensejo. O presente texto visa estudar estes poemas, como contribuição para responder à pergunta: existe um orientalismo modernista em Portugal? Sabemos que a pergunta equivalente se colocou com bastante pertinência, por exemplo, em contexto anglo-saxónico, tendo em conta o interesse de Ezra Pound pela literatura chinesa e japonesa. Mas será que a questão se coloca com igual validade no contexto português?

Antes de começar, resta-me salientar que o modelo teórico pelo qual encaro o fenômeno orientalista parte de Edward Said que, apesar de suas conhecidas limitações, me parece ser um modelo bastante válido. No encalço deste autor, entenderei o orientalismo como um conjunto de referências autossuficientes, funcionando como discurso - de natureza ou finalidade histórico-cultural ou estética - independente sobre um Outro. $\mathrm{Na}$ medida em que as proposições de natureza ontológica são geradas no seio desse discurso, dispensam por isso a verificação no mundo real do seu valor de verdade. Por exemplo, acredita-se que o (elemento ou homem) oriental é naturalmente indolente, lascivo, esteta, pomposo; mas também irracional, ascético, místico, religioso, etc. Ou seja, no orientalismo interessa sobretudo a construção e perpetuação interna de um discurso. Mesmo que estes atributos tenham ocorrido em associação a um qualquer elemento chinês, persa, turco, num dado momento da história, o discurso orientalista estabiliza ontologicamente tais estereótipos: fazem parte do ser do "oriental".

\section{Opiário ou a Europa que regressa do Oriente}

“Opiário", primeira aparição em letra de forma assinada por Álvaro de Campos, publica-se no primeiro número de Orpheu junto com a "Ode Triunfal". Neste poema é

\footnotetext{
${ }^{5}$ Neste ensaio, citarei a partir da primeira edição, de 1915.
} 
relatada a situação a bordo de um navio que regressa de um cruzeiro que o jovem engenheiro Álvaro de Campos faz à Índia e à China. Fernando Pessoa, ao construir em "Opiário" o personagem Álvaro de Campos, está a trabalhar com o motivo decadentista do esteta na Ásia, em busca de opiáceos. Contudo, o poema propõe um distanciamento ou mesmo uma paródia disto, uma vez que Campos não vai ao Oriente buscar ópio, mas, ao contrário, como se pode ler na primeira estrofe, busca um Oriente no ópio: ou seja, trata-se de um Oriente interior. Interessa considerar, nesta reapropriação do motivo da opiomania, tanto o jogo com as literaturas decadentistas inglesa ou francesa quanto a alusão indireta a Camilo Pessanha enquanto esteta exilado na Ásia.

Assim, o orientalismo pode iluminar a importância deste texto, geralmente "despachado" como um poema que existe apenas para fazer da "Ode Triunfal" o produto de uma conversão, e permite colocá-lo num plano mais vasto: uma meditação sobre os rumos de uma Europa exaurida e errante, alegorizada como um navio que regressa do Oriente. Com efeito, se entendermos que a viagem marítima de "Opiário" diz respeito a um regresso coletivo de uma Europa errante, neste contexto, o Português, simbolizado por Álvaro de Campos, é individualizado do rol das pátrias como o desempregado da Europa ou mesmo da própria História:

Pertenço a um genero de portuguêses Que depois de estar a India descoberta Ficaram sem trabalho. A morte é certa. Tenho pensado nisto muitas vêzes (PESSOA, 1915, p. 74).

Nesta passagem, as Descobertas representam o momento a partir do qual Portugal passa a existir fora da História, uma vez que esta o expulsa do concerto das nações depois de cumprida a "missão" de descoberta da Índia. Contudo, a Índia não deixa de ser figura de uma virtualidade imperial, sempre por atualizar e sempre transcendente aos seus condicionamentos materiais. Neste sentido, "Opiário" não deve ser lido como mera retoma dos tópicos finisseculares da decadência e do Decadentismo, mas como um dos textos que sinalizam um prolongamento - que a década de 1910 revela em Fernando Pessoa - em termos de reflexão em fragmentos ensaísticos acerca das categorias de "decadência", 
"decadente" e literatura decadente" ${ }^{6}$, sobretudo se tivermos a presença do poema-irmão, a "Ode Triunfal".

A junção dos dois textos, desirmanados pela maior parte das leituras críticas, permite a leitura complementar, como a de Fernando Cabral Martins (2008), que vê nos dois Álvaros do primeiro Orpheu uma demonstração do que Pessoa, na produção crítica sobre correntes por ele criadas como o "Dinamismo", assinala como resultado de um "enthusiasmo excessivo pela saude que sempre distinguiu certas especies de decadentes" (PESSOA, 2009, p. 421). Deste modo se torna possível olhar para "Opiário" como exemplo, talvez único, de uma espécie de poema meta-decadentismo operado no contexto do surto dos ismos.

Outro aspecto essencial do poema é a forma como ele se relaciona com o discurso orientalista enquanto registro eminentemente estético. O poema possui, aliás, várias alusões discretas, como as da seguinte quadra, a motivos e temas orientalizantes, a saber: o mandarim, o chá, e a figura de Salomé e João Batista (o Precursor):

Vou cambaleando através do lavôr Duma vida-interior de renda e láca. Tenho a impressão de ter em casa a fáca Com que foi degolado o Precursor (PESSOA, 1990, p. 71).

A referência à "renda e láca" recicla de forma paródica motivos estéticos também presentes nas artes plásticas europeias de inspiração chinesa e japonesa, as chamadas chinoiserie e japonaiserie, introduzindo assim um sinal de distanciamento irónico face ao discurso esteticista orientalista, bem como uma alusão paródica ao decadentismo, um pouco ao modo do poema em prosa "Taça de Chá”, de Almada Negreiros, que em seguida tratarei. De qualquer forma, esta poética da simultânea apropriação e recusa de tradições

\footnotetext{
${ }^{6}$ Pessoa aponta, neste texto não-datado, para o surto de um Decadentismo sintético, de que Orpheu seria já um sinal: "As correntes neoclassicas serão provavelmente as mais fortes. Eu, poeta decadente, creio que assim será. [\#] Como expressão da dysgenica da guerra, apparecerão correntes ultra-decadentes, interpretativas do abatimento em que grande parte ficará. São trez essas correntes, consoante reajam contra o spirito de organisação, contra o spirito revolucionario, ou contra os dois simultaneamente. O primeiro typo de decadentismo será uma continuação, differente por novas individualisações apenas, d'aquella parte do decadentismo que representa uma revolta contra as regras, uma introspecção excessiva. O segundo typo de decadentismo será uma continuação d'aquelle tipo de decadentismo que mais se occupa em criar uma indiferença aos problemas do meio, do que em se entregar á introspecção propriamente. O primeiro partirá de Verlaine, como o segundo de Mallarmé ou dos chamados esthetas inglezes, Pater ou Wilde. O terceiro typo de decadentismo é que trará novidades; será uma exacerbação dos dois reunidos: qualquer prenuncio delle surgiu, de resto, já antes da guerra, na corrente portugueza que veio depois a manifestar-se em ORPHEU [sic]" (PESSOA, 2009, p. 420).
} 
literárias, comportando elementos da natureza do pastiche, remete para o princípio sensacionista de abarcar todas as estéticas. Pessoa apropria-se do Decadentismo, tornandoo em outra coisa.

Contudo, estas esparsas referências são algo inconsistentes enquanto tentativa de criar uma estética orientalista definida. Desta maneira, é possível ler tais motivos enquanto alusões irônicas ao discurso orientalista em si mesmo. "Opiário", lidando de forma irónica com a ideia de fuga para o Oriente, é um poema que se propõe trabalhar com citações de estereótipos, um pouco ao modo do Mandarim (1880) de Eça de Queirós. Na verdade, o que estas duas obras têm em comum, além de um Oriente nunca visitado pelo autor empírico, seria a necessidade de desconstruir ou mesmo de esvaziar um discurso a partir de dentro. Assim, quando Campos afirma: "Enoja-me o Oriente. É uma esteira/ Que a gente enróla e deixa de ser bela" (PESSOA, 1990, p. 59) ou "Nasci pra mandarim de condição,/ Mas faltam-me o sossego, o chá e a esteira" (PESSOA, 1915, p. 61), a forma como a desilusão face ao Oriente é aqui encenada aponta para essa relação crítica, não tanto com o Oriente mas com o próprio discurso orientalista.

Em suma, em "Opiário", o Oriente parece apenas interessar enquanto imagem desconstruída, enquanto figura de uma crença ou afeição que não resultam, ideia que ganha corpo na exploração que o poema promove da noção de desilusão. Como o heterónimo afirma em um outro momento:

Eu acho que não vale a pena ter Ido ao Oriente e visto a India e a China. A terra é semelhante e pequenina E ha só uma maneira de viver (PESSOA, 1915, p. 72).

É de notar que nada, em todo o poema, se debruça ou se dirige a esse outro que existe nessa "India" ou nessa "China". A única figura da alteridade no poema é o outro europeu que segue no navio junto com o sujeito lírico. Quem se desloca ao Oriente será desiludido pela mesmidade do que irá encontrar. Assim, no poema não chega sequer a existir o propósito de criticar a perspectiva europeia acerca dos seus outros, tendo como contrapeso a necessidade de os conhecer de forma mais justa. Neste sentido, o campo crítico do poema cinge-se ao das projeções do si sobre um outro, isto é, ao orientalismo e sua leitura. Todavia, enquanto puro exercício orientalista, "Opiário" é um questionamento dos próprios fundamentos de tal discurso. 
Interessa, contudo, a Campos fazer a viagem de modo a encontrar a própria desilusão de a haver feito. A China e a Índia devêm, nesta lógica, como símbolos da vaidade de tal esforço. "Opiário" parece, assim, sugerir que não vale a pena deixar a narrativa poética construída em torno da Índia para ir conhecer a Índia, uma vez que é possível que esta não exista fora do poema.

\title{
3. O distante Oriente de Mário de Sá-Carneiro
}

Passo agora à leitura de um trecho do poema de Mário de Sá-Carneiro, intitulado "Distante Melodia..." e que consta do mesmo número de Orpheu:

\author{
(...) \\ Balaústres de som, arcos de Amar, \\ Pontes de brilho, ogivas de perfume... \\ Domínio inexprimivel d'Ópio e lume \\ Que nunca mais, em côr, hei-de habitar... \\ Tapêtes doutras Persias mais Oriente... \\ Cortinados de Chinas mais marfim... \\ Aureos Templos de ritos de cetim... \\ Fontes correndo sombra, mansamente... \\ Zimbórios-pantheons de nostalgias, \\ Catedrais de ser-Eu por sobre o mar... \\ Escadas de honra, escadas só, ao ar... \\ Novas Byzancios-Alma, outras Turquias... \\ (SÁ-CARNEIRO, 1915 p. 13)
}

Note-se, antes de mais, como o Oriente, desdobrando-se numa série de ambiências múltiplas e propositadamente pouco estruturadas, fornece uma série de objetos concretos que como se afundam nessas paisagens indeterminadas: tapetes, cortinados, templos. Todos estes motivos possuem forte valor epocal, também ocorrendo em poetas “orientalistas" próximos do surto modernista, como Alberto Osório de Castro, Alfredo Guisado e Ângelo de Lima.

A confusão referencial que avulta nos textos de todos estes autores, com envios à Índia, à China e ao Egito, pode ser lida segundo o que Jan Hokenson (2004) designou como "pan-orientalismo", no sentido em que o que interessa neste tipo de amálgama referencial não é um qualquer "exotismo" espacial, mas um clima difuso composto de 
fragmentos ou de rastos de vários orientes. Os modernistas portugueses - e sobremaneira o poeta de Indícios de Ouro - acentuam este Oriente desligado de um conhecimento in loco e que é mais um ambiente do que um cenário preciso. Esta linha afasta-se então da relação explícita com a presença da Ásia na cultura e na história portuguesas. São poetas essencialmente receptivos a um Oriente já orientalizado em segunda mão pela poesia francesa, e por outros poetas como Eugénio de Castro, como parece ser o caso de SáCarneiro. Já nos poetas com a experiência da vivência local, como Pessanha, o que temos é uma demorada atenção que confere mais densidade referencial e espessura ao seu Oriente, até porque no caso de todos eles o interesse é acompanhado por outra produção textual.

Por outro lado, o Oriente exerce aqui, neste poeta, um papel concreto. No autor de Dispersão, a encenação prazerosa da frustração de um Eu impossível, um dos vetores temáticos fundamentais de sua poesia, concretiza-se nesta visão de uma paisagem interior aos sentidos e à consciência. Diz o sujeito poético em momento anterior do poema: "Então os meus sentidos eram côres/ Nasciam num jardim as minhas ânsias" (SÁCARNEIRO, 1915, p. 13). Neste poema publicado no primeiro número de Orphen, o Oriente é um signo ao mesmo tempo da realeza e do fausto desse Eu cuja distância se tornou inalcançável. Neste sentido, como é típico deste poeta, o bric-a-brac oriental que é criado ("Tapêtes doutras Persias mais Oriente... /Cortinados de Chinas mais marfim...") é também postiço, ao se revelar sinal da inconsistência do sujeito.

Assim, se as referências ao Oriente constituem em Alfredo Guisado ou no Pessoa de "Chuva Oblíqua" um signo do mistério, em Sá-Carneiro elas remetem antes para o esplendor de um país perdido, a própria "Byzancio-Alma" que é necessário retomar em sua realeza bárbara ou exótica. Ora, isto seria um bom retrato do que Pessoa considerou ser a linha superior de exotismo na arte, nada mais do que uma interiorização da realidade em "sonho". Definindo a "arte moderna" como arte de interiorização face a um mundo já totalmente conhecido e explorado, Pessoa propõe, num fragmento ortónimo não datado publicado por Jeronimo Pizarro (mas provavelmente da década de dez), a transformação da realidade em sonho como sendo superior à fuga egótica para o "longe no espaço, quér para o extranho e o invulgar na vida - o Longe na vida afinal" (Pessoa, 2006, p. 388). Este seria, para ele, o caso do escritor francês Pierre Loti, em sua "fuga" para o Oriente. Retomando o tom dos ensaios, publicados em 1912 n'A Águia, sobre a Nova Poesia Portuguesa, é assim que descreve aquela transformação: 
Mettendo esse ruidoso mundo, a natureza, tudo, dentro do proprio sonbo - e fugindo da "Realidade" nesse sonho. É o caminho portuguez (tão caracteristicamente portuguez) - que vem desde Anthero de Quental cada vez mais intenso até á nossa recentissima poesia (PESSOA, 2006, p. 388).

O que as "Persias mais Oriente" - fórmula na qual o substantivo se torna adjetivo do poeta de Dispersão mostram parece ser um aspecto desta proposta crítica pessoana, apontando para um devir do Oriente como uma propriedade, isto é, um repositório de imagens e de temas servindo um movimento simbólico. Expressões como "Novas Byzancios-Alma, outras Turquias...” (Sá-Carneiro, 1915, p. 13) são assim, a bem dizer, declinações imagéticas da noção-imagem pessoana de "Índia nova" (Pessoa, 2000, p. 67)", não só por acusarem a presença dos mesmos qualificativos (e da conjunção "mais") que se encontram em Pessoa, mas por, de igual modo, implicarem uma transferência para um plano interior, percepcionado como superior ou transcendente ao plano histórico, deste modo alheio ao Oriente enquanto conjunto de imagens bem definidas do ponto de vista histórico e geográfico. Tal fica claro na passagem do substantivo (ou da substância) a adjetivo (a qualidade) no verso de Sá-Carneiro, embora não seja a dimensão coletiva e nacional - ao modo do Pessoa dos ensaios de 1912 - que é visada por Sá-Carneiro, antes a experiência de um sujeito individual.

\section{Almada e a écfrase desconstruída}

O mesmo impulso desconstrutivo que está na base de "Opiário", fazendo dele um texto muito pensado, existe também em Almada Negreiros, no poema em prosa ou microconto: “A Taça de Chá”, também publicado no primeiro número da revista:

O luar desmaiava mais ainda uma máscara caída nas esteiras bordadas. E os bambús ao vento e os crysanthemos nos jardins e as garças no tanque,

\footnotetext{
7 Trata-se de uma expressão introduzida por Pessoa nos artigos publicados entre setembro e dezembro de 1912, em A Águia: "E a nossa grande Raça partirá em busca de uma Índia nova, que não existe no espaço, em naus que são construídas 'daquilo de que os sonhos são feitos'. E o seu verdadeiro e supremo destino, de que a obra dos navegadores foi o obscuro e carnal ante-arremedo, realizar-se-á divinamente" (Pessoa, 2000, p. 67). Aqui, Pessoa apela ao que seria a necessidade do País a conquistar o que ele designa como uma "Índia nova", que é abertamente uma construção simbólica e literária. Porém, o seu discurso neo-épico propõe a esfera cultural ou literária como campo privilegiado de ação.
} 
gemiam com elle a adivinharem-lhe o fim. Em róda tombávam-se adormecidos os idolos coloridos e os dragões alados. E a gueisha, porcelana [sic] transparente como a casca de um ovo da Ibis, enrodilhouse num labirinto que nem os dragões dos deuses em dias de lagrymas. E os seus olhos rasgados, perolas de Nankim a desmaiar-se em agua, confundiam-se scintillantes no luzidio das porcelanas.

Ele, num gesto ultimo, fechou-lhe os lábios co'as pontas dos dedos, e disse a finar-se: - Chorar não é remedio; só te peço que não me atraiçoes emquanto o meu corpo for quente. Deixou a cabeça nas esteiras e ficou. (...)

Pela manhã vinham os vizinhos em bicos dos pés espreitar por entre os bambús, e todos viram acocorada a gueisha abanando o morto com um leque de marfim.

A estampa do pires é igual. (NEGREIROS, 1915: 59)

Note-se, antes de mais, a presença de um pan-orientalismo muito semelhante ao de Sá-Carneiro, confundindo referências chinesas (os bambus, Nanquim), japonesas (a gueixa, os crisântemos), mas também egípcias, como a ave íbis. Ou seja, o que interessa neste texto é a sugestão de um mundo totalmente fantasioso. A estrutura anedótica desta história fica denunciada pela súbita revelação da écfrase: “A estampa do pires é igual”. A cena é de uma porcelana, portanto, o que já havia sido sugerido na descrição da figura feminina, em miseen-abime, pintada por Almada como "porcelana transparente como a casca de um ovo da Ibis".

Neste texto a mediação, ou o filtro, europeia face às referências orientais é sobretudo francesa, o que não admira, pois é a França a grande difusora da chinoiserie, mas também da japonaiseire, isto é, do colecionismo de objetos decorativos desses países ${ }^{8}$. A primeira é justamente uma moda francesa, proveniente da sinofilia da época das Luzes, segundo Mackerras (1989, p. 43). As coleções de chinoiseries resultariam do incremento das trocas comerciais iniciadas dois séculos antes pelos portugueses, cuja mediação foi a partir do século XVII disputada pela Companhias Francesa das Índias Orientais e outras Companhias. Já a japonaiserie fez sua grande aparição na Exposição Mundial de Paris, em 1867.

Curiosamente, lembra Appleton (1951, p. 94) que muita da porcelana que circulava nos mercados europeus no século XIX, até mesmo a chinesa, seria importada por pintar do Leste asiático e posteriormente pintada na Europa de acordo com o gosto europeu, com

\footnotetext{
8 Se bem que os termos chinoiserie ou japonaiserie não se limitam às artes plásticas, como nota Marta Pinto (2013, p. 108) ao invocar o poema «Chinoiserie» de Théophile Gautier (1811-1872), (c.1835), publicado em La Comédie de la mort (1838), que traz para a literatura a ideia de coleção de pequenos objetos que enforma esteticamente o poema em prosa, de acordo com a lição sinestésica finissecular.
} 


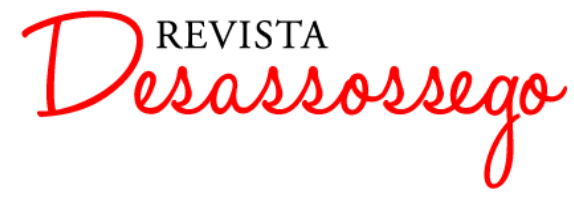

DESASSOSSEGO 15 | JUN/2016 | ISSN 2175-3180

DOI: http://dx.doi.org/10.11606/issn.2175-3180.v8i15p17-29

paisagens estereotipadas de salgueiros, palmeiras e pagodes. Ora, algo de semelhante, ainda que a outro nível, se diria passar neste texto de Almada: toda a China/Japão que aqui estão são postiços e não o procuram esconder, pintados que são por uma mão europeia. Revela-o o patético e o cómico da cena, micro-paródia de um Romeu e Julieta orientais, pintados à pressa com uma paisagem extremo-oriental no entorno.

O que este texto tem de proposital confusão sobre o que é o Extremo-Oriente fica claro na paródia das linguagens orientalistas que o move, desde os estereótipos mais básicos ("bicos de pés, olhos rasgados") até à intromissão do fantástico ("os ídolos coloridos e os dragões alados"), e ainda à inversão do tema da fidelidade inabalável da viúva, tão característico do mundo sínico. Por isso, o poema deve ser lido, tal como os outros dois, como uma forte desconstrução do orientalismo, neste caso pelo viés da paródia. A sua linguagem caricatural tem a função de alertar para a violência da própria estereotipificação, mas não pelo bem do chinês e do japonês, forçados a um retrato estereotipado. Não me parece que, tal como em "Opiário", a desconstrução do orientalismo vise combater o orientalismo enquanto representação distorcida ou errónea. $\mathrm{O}$ gesto de Almada - a meu ver preocupado apenas com a perspectiva europeia - antes visa, parece-me, pôr nu o aborrecimento que a estética chinesa e japonesa já causava na Europa, ao ser reproduzida em massa, e totalmente falsificada, como há pouco alertara Wenceslau de Moraes, em $A$ Vida japonesa (1905):

Enviam-se para a Europa porcelanas fabricadas em Nagóia, cuja ornamentação artística é aplicada por processos de decalcomania, vindo tais ornamentações da própria Europa. (...) são tão horrendos os artigos de exportação (...) que estou convencido de que os charões pelintras da França e da Alemanha estão já sendo preferidos aos japoneses. [...] quando se leve em conta o finíssimo sentimento estético de que dá provas cada japonês - devemos concluir que será com profundo asco que o operário [Japonês] se submete ao vil emprego de copiar os desenhos que lhe enviam do Ocidente e de baratear os seus produtos a ponto de torná-los detestáveis. (MORAIS, 1985, p. 274-277)

Por aqui se explica a última frase do poema, que não é a revelação ingénua de uma vertente intersemiótica ou ecfrástica, mas a afirmação da violência da repetição por detrás do gesto artístico: “A estampa do pires é igual”. O carácter seco e abrupto da frase decalca a violência da própria noção de repetição que dá existência a um objeto que, ao modo da consabida leitura de Walter Benjamin, perdeu a aura. A porcelana e a estética que, 
literalmente, é nele impressa são deste modo denunciadas como linguagens esvaziadas, sobretudo ao serem fortemente conotadas com o decadentismo francês e sua proposta de evasão do mundo pelo culto do artificialismo dos objetos raros e de coleção. Tal é conduzido por um registro orientalista autoconsciente da sua própria perversidade, o que, como terá ficado claro, constitui o movimento central do texto.

\section{Considerações finais}

A minha argumentação sustentou que o orientalismo que se encontra estes textos não é um mero rastro das estéticas finisseculares num contexto de Vanguarda, mas um fenômeno mais complexo e de algum modo ingénuo. E penso ter, assim, ficado claro que o que encontro de comum nestes três textos é a sua vertente desconstrutiva do orientalismo, não só enquanto estética, mas também enquanto discurso, o que significa que o primeiro número de Orpheu tem implícita uma reflexão conjunta do orientalismo, construindo uma revisão - no duplo sentido de síntese e revisão crítica - desta estética na literatura portuguesa.

Fazendo uso de uma famosa expressão de Edward Said, o Oriente modernista português já nasce orientalizado, isto é, claramente construído ou, no mínimo, mediado por outros discursos orientalistas, como pela poesia finissecular francesa, mas também pela partilha de uma cultura esotérica, para a qual o Egito é uma referência importante, sobretudo em Pessoa, mas também, mais tangencialmente, em Mário de Sá-Carneiro e Ângelo de Lima, poetas em que tais referências ajudam a construir a ambiência hierática dos ritos mistéricos e iniciáticos?

Com efeito, não interessa a estes poetas que trabalhámos (mas também a Ângelo Lima, a Guisado e ao Pessoa de "Chuva Oblíqua") declinar os mundos orientais em sua variedade geográfica e cultural, como faria o esteta em viagem, mas usá-los como pretexto para uma ambiência misteriosa. Assim, se há um orientalismo modernista (português), ele não participa do particular, mas dirige-se a uma noção geral, de timbre imaginário e fantasioso, de Oriente. Na periferia inevitável com o Saudosismo e outras estéticas neorromânticas (o que fica claro em Alfredo Guisado, por exemplo), o Modernismo português faz do imaginário orientalista uma poética do indeterminado. O Oriente devém no poema como o sinal de uma ambiência conotada com o hierático, o raro, fornecendo material para

\footnotetext{
${ }^{9}$ Sobre esta questão cf. GEBRA (2015).
} 


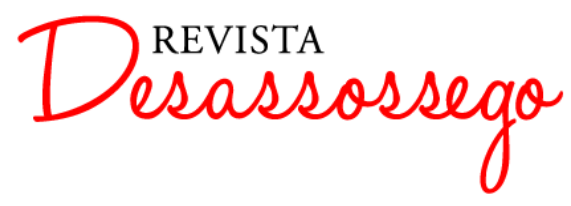

DESASSOSSEGO 15 | JUN/2016 | ISSN 2175-3180

DOI: http://dx.doi.org/10.11606/issn.2175-3180.v8i15p17-29

arriscadas sinestesias, funcionando assim o Oriente enquanto categoria abstrata e simbólica que, de alguma maneira, remete para a ritualidade do próprio poema ou da escrita.

\section{Bibliografia}

APPLETON, William W. "English Chinoiserie". In: . A Cycle of Cathay - The

Chinese Vogue in England during the Seventeenth and Eighteenth Centuries. Nova Iorque: Columbia University Press, 1951, p. 90-120.

FERRO, António (ed.). Orpheu. Revista Trimestral de Literatura. Ano 1, n. ${ }^{\circ}$ 1, Janeirofevereiro-março, Lisboa: Tipografia do Comércio, 1915.

GEBRA, Fernando de Moraes. "Do Nilo ao Tejo: o Egito em Orpheu”. Nau Literária: crítica e teoria de literaturas, vol. 11 n. ${ }^{\circ} 02$ - jul/dez 2015, 1-23.

MARTINS, Fernando Cabral. "Opiário". In: (org.). Dicionário de

Fernando Pessoa e do Modernismo Português. Lisboa: Caminho, 2008, p. 563.

HOKENSON, Jan Walsh. Japan, France, and East-West Aesthetics. French Literature, 18672000. Madison NJ: Fairleigh Dickinson University Press, 2004.

MACKERRAS, Colin. Western Images of China. Oxford, Nova Iorque e Hong Kong: Oxford University Press, 1989.

MORAES, Wenceslau de. A Vida japonesa - terceira série de cartas do Japão (1905-1906). Porto: Lello \& Irmão, 1985.

PESSOA, Fernando. Crítica. Ensaios, Artigos, Entrevistas. Fernando Cabral Martins (ed.). Obras de Fernando Pessoa. Lisboa: Assírio \& Alvim, 2000.

Escritos sobre Génio e Loucura, tomos I e II. Ed. Jerónimo Pizarro.

Edição Crítica de Fernando Pessoa, Série Maior, volume VII. Lisboa: Imprensa NacionalCasa da Moeda, 2006.

. Sensacionismo e Outros Ismos. Ed. Jerónimo Pizarro. Edição Crítica de

Fernando Pessoa, Série Maior, volume X. Lisboa: Imprensa Nacional-Casa da Moeda, 2009.

PINTO, Marta. Traduzir o outro oriental: a configuração da figura feminina na literatura portuguesa finissecular: (António Feijó e Wenceslau de Moraes). Tese de doutoramento, Tradução (História da Tradução), Universidade de Lisboa, Faculdade de Letras, 2013.

SAID, Edward. Orientalismo. Lisboa: Cotovia, 2004. 